\title{
ENTREVISTA COM GILTON MENDES DOS SANTOS
}

\section{INTERVIEW WITH GILTON MENDES DOS SANTOS}

Ricardo Rella ${ }^{3}$

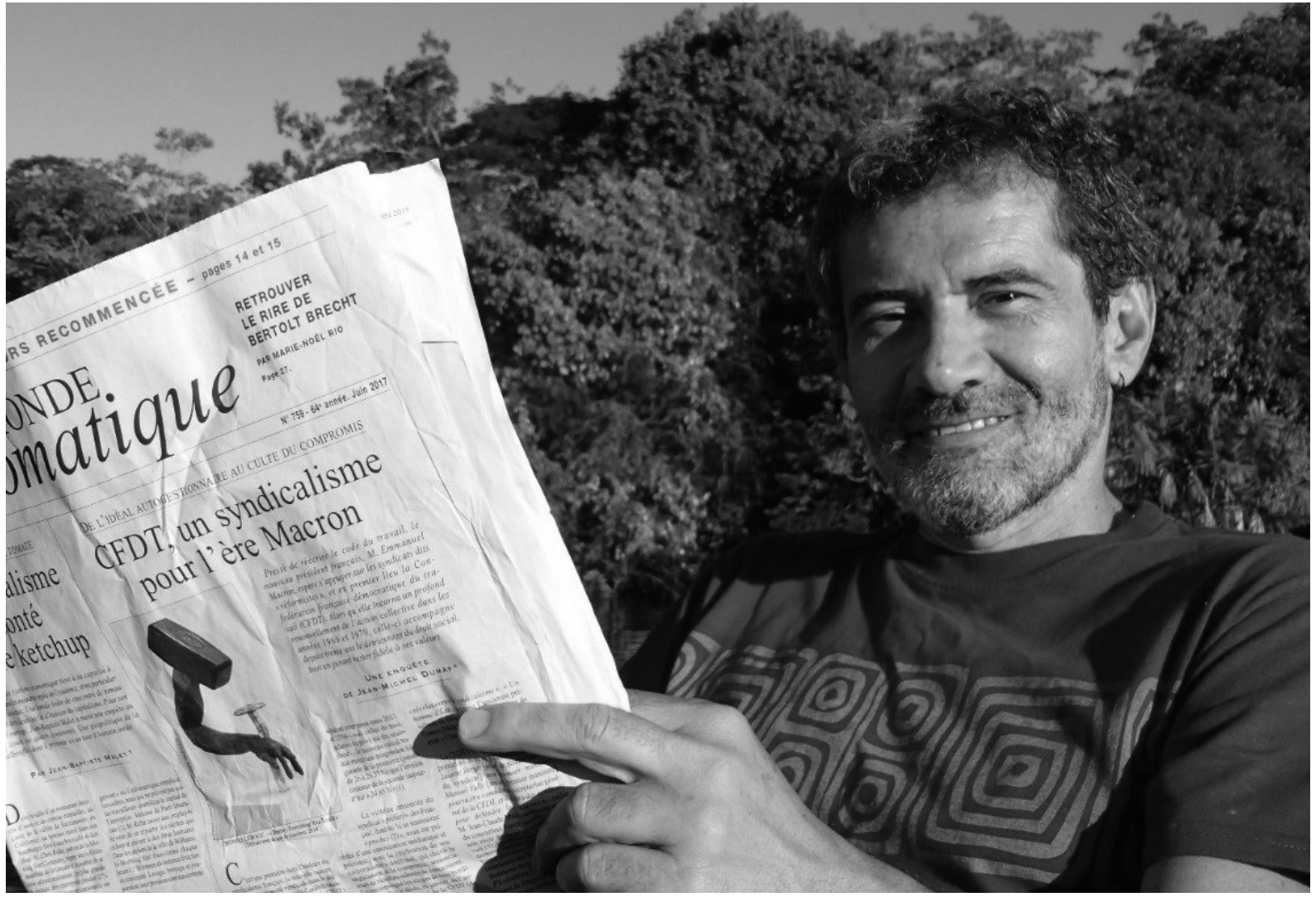

Gilton Mendes dos Santos é professor do Departamento de Antropologia da Universidade Federal do Amazonas (UFAM) e coordenador do Núcleo de Estudos da Amazônia Indígena (NEAI/PPGAS). Conduziu pesquisas por vários anos sobre ecologia e cosmologia entre os Enawene-Nawe e os Rikbaktsa, na Amazônia Meridional. Atualmente se dedica à reflexão antropológica em parceria com estudantes indígenas e realiza pesquisas sobre a relação gente - planta na Bacia do Purus e no Alto Rio Negro. Foi organizador do livro Álbum Purus (Edua, 2012) e Redes Arawa. Ensaios de etnologia do Médio Purus (Edua, 2016) e de vários artigos sobre antropologia da natureza e relação natureza/cultura.

${ }^{3}$ Doutorando em Antropologia Social na Universidade Federal do Amazonas (UFAM). Editor-executivo da Revista Wamon 


\section{Qual foi sua formação acadêmica? Como acabou trabalhando com cosmologias indígenas?}

Infelizmente eu não sou (ou fui) uma dessas pessoas que sabe o que quer da vida (profissional) logo cedo. Na flor da juventude, a gente quer conhecer e experimentar diferentes possibilidades, trilhar por vários caminhos antes de uma decisão definitiva sobre qual carreira a seguir. Mas, como acontece com a maioria, eu fui obrigado a escolher um curso e uma profissão sem a clareza necessária e dentro das opções que me foram ofertadas pela única universidade do meu Estado à época. Assim, eu ingressei no curso de Agronomia na Universidade Federal do Mato Grosso (UFMT), em Cuiabá. Fiz esta opção porque gostava das ciências da natureza, e, com a Agronomia, eu teria ainda certa segurança em termos de atuação futura no mercado de trabalho. Durante o curso me deparei com uma perspectiva rica desta área do conhecimento, que diz respeito à interação inteligente e equilibrada entre o homem e o ambiente, embora em sua quase totalidade a Agronomia seja voltada para o capital e o investimento pesado na produção de monoculturas a partir de um pacote tecnológico perverso, que inclui máquinas pesadas, sementes híbridas e transgênicas, agrotóxicos e tantos outros venenos perpetrados por esta visão dominante na área. Bem, foi este curso, ambíguo e encharcado de desafios que levei, às duras penas - como uma provação e um desafio pessoal - até o fim. Durante a graduação eu me envolvi com várias frentes e atividades interessantes, desde o movimento estudantil até a luta pela Reforma Agrária, ainda muito latente à época. Assim que terminei o curso de Agronomia, fiz parte de uma pequena equipe de pesquisa que iria estudar uma sociedade indígena monolíngüe, com uma população em torno de 120 pessoas, das quais apenas três tinham ido até então a uma cidade. Refiro-me aqui aos Enawene-Nawe, um povo de língua Arawak, habitante do Alto Rio Juruena, no noroeste do Mato Grosso, numa região de transição entre o Cerrado e a Floresta Tropical. Minha tarefa nesta equipe, grosso modo, era compreender, digamos, um ciclo agrícola e de coleta ao longo de um ano. Nesta altura, eu já tinha lido e me familiarizado com alguns temas da Antropologia e conhecido alguns (poucos) antropólogos. Adorava ouvir e saber dos assuntos sobre Etnologia e das teorias explicativas para certos fenômenos da vida social. Da equipe deste projeto participava o professor de lingüística (UNICAMP) Marcio Silva, recém doutorado em Antropologia e ávido pela disciplina. Marcio era um jovem especialista em parentesco, e estava incumbido de estudar este assunto entre os Enawene-Nawe. Minhas primeiras aulas de antropologia foram no campo, in loco, ouvindo Marcio explicar o que era consangüinidade e afinidade. Estas categorias, inclusive, me ajudaram a compreender como se organizava a prática agrícola entre aquele grupo. Mas, algo mais radical causou uma transformação em mim: assistir homens e mulheres conversarem, tocar flauta e ofertarem comida às plantas na roça, me deparar com um xamã (sotayriti), com uma pequena bola de algodão entre os dedos, à procura de uma "alma", cativa pelas plantas de mandioca. Foi esta experiência que me remeteu inexoravelmente à Antropologia. Eu queria entender melhor estas coisas, que nunca tiveram lugar na Agronomia. Resistente, no entanto, à carreira acadêmica, somente alguns anos depois fui procurar o professor, e também amigo dos tempos de campo, Marcio Silva, que havia, a pouco tempo, ingressado no Departamento de Antropologia da UNICAMP, para fazer o mestrado sob sua orientação, com um projeto propondo um diálogo entre etnologia e agronomia. Foi neste contexto que descobri que minha pesquisa tinha a ver com o que a Antropologia chamava de cosmologia. Assim que terminei o Mestrado, ainda sem ter defendido a dissertação, fui aprovado no doutorado, na USP, para onde já havia também migrado Marcio Silva, e que continuou me orientando. Meu projeto de doutoramento ambicionava uma comparação sobre a relação Natureza/Cultura entre os Enawene-Nawe e os Rikbaktsa, um povo vizinho, mas historicamente inimigo dos Enawene-Nawe, falante da língua Macro-Jê e uma vida cultural completamente distinta da que eu conhecia. Depois de quatro meses ininterruptos de pesquisa de campo, cheguei à conclusão de que não teria fôlego para o que havia proposto, e voltei ao "meu 
grupo" para compreendê-lo melhor, defendendo uma tese subintitulada "cosmologia e ecologia entre os Enawene-Nawe", defendida no ano de 2006. Termo simpático, quase elegante, cosmologia parece não apresentar uma linha temporal profunda na tradição etnológica. Se não me falha a memória, ela não aparece, ou pouco aparece, nos quase três mil títulos e resumos constituintes dos dois fartos volumes da Bibliografia Critica da Etnologia Brasileira, de autoria do antropólogo alemão Herbert Baldus, organizados nas décadas de 1950 e 1960. Até então com seu conteúdo subsumido a outros epítetos, cosmologia tem sido, atual e abundantemente, empregada na antropologia para abordar tanto a narrativa nativa de uma concepção metafísica sobre as estruturas do universo quanto para explorar o sentido deste nos objetos, nos espaços (pátio, casa, roça), bem como para explicar as concepções sobre o corpo, sua composição, seu devir post-mortem e suas relações com o cosmos e os seres que nele habitam. O que tentei explorar em minha pesquisa entre os Enawene-Nawe foi um pouco de algumas dessas dimensões do sentido de cosmologia.

\section{Como amadureceu sua atuação como pesquisador no contexto amazônico e na UFAM em particu- lar?}

Minha opção foi por continuar os estudos sobre os povos indígenas em outros contextos etnográficos, especialmente na Amazônia. Em 2006 eu me mudei para Manaus para trabalhar no recém-criado Departamento de Antropologia da UFAM. Neste ano, encontrava-se aberto um edital da Fundação de Amparo à Pesquisa do Estado do Amazonas (FAPEAM) de apoio a "primeiros projetos". Então resolvi encaminhar uma proposta intitulada "Amazonas Indígena: um mapeamento da produção bibliográfica e das instituições atuantes junto aos povos indígenas no Estado". Além dos objetivos imanentes e explícitos no próprio projeto, a proposta carregava também um interesse muito pessoal, isto é, de conhecer, sobretudo, o que havia sido escrito sobre os povos localizados no estado do Amazonas, que até então eu pouco sabia. Aprovado, este projeto, coordenado por mim, contou com a participação de cinco outros colegas, professores do Departamento de Antropologia, e cerca de 15 estudantes bolsistas de Iniciação Científica de diferentes cursos de graduação da UFAM. O projeto findou em 2009, deixando um banco de dados que possibilitou uma série de análises temáticas e um mapa que localizava toda a produção bibliográfica e audiovisual realizada até então. Foi nesse contexto que apareceu uma região da Amazônia, ocupada por uma constelação de pequenos povos, sobre a qual havia pouca investigação antropológica, a bacia do Purus. Isso me convenceu, de uma vez por todas, de que seria aí o lugar de atenção dos meus investimentos acadêmicos. A partir desse momento, passei a estimular meus alunos, de graduação e pós-graduação, a desenvolverem suas pesquisas sobre os grupos dessa região. Ao longo desses anos, foram levados a cabo vários projetos de pesquisa, coletivos e individuais, atividades de extensão, uma expedição científica, vários seminários de pesquisa, publicação de artigos e de três importantes coletâneas e textos de alunos e pesquisadores etnólogos estudiosos dos grupos indígenas desta bacia: o livro Álbum Purus (2010), sob minha organização, o livro Paisagens Ameríndias (2013), editado por mim e pela antropóloga da USP, Marta Amoroso, e a obra Redes Arawa (2016), organizada por mim e pelo meu ex-aluno de mestrado, agora professor de antropologia na Universidade Federal do Oeste do Pará (UFOPA), Miguel Aparicio. Em 2014 eu decidi realizar meu pos-doutorado na Universidade de Nanterre, na França, com o intento de dedicar um tempo a sistematizar as informações e o material etnográfico levantados sobre os grupos do Purus. Talvez ainda impregnado pela formação de graduação, e pelo fracasso no diálogo entre Agronomia e Etnologia, que havia proposto desde o meu ingresso na Antropologia, eu estava interessado numa "história da agricultura no Purus", a entender a importância da mandioca e a prática do cultivo, bem como o papel e o sentido da coleta nos seus sistemas de conhe- 
cimentos desses grupos. Ao observar de perto, e com atenção essa história, fui surpreendido por uma realidade regional que me mostrou que o sistema extrativista de aviamento, iniciado no século XIX, aliado à política do Serviço de Proteção ao Índio (SPI), foi responsável por uma transformação significativa nos modelos de relação desses povos com a floresta e seus recursos vegetais e animais, implantando um esquema de plantio de mandioca do tipo plantation e a produção de farinha em larga escala, com fins ao abastecimento dos seringais da região. Mais ao fundo, porém, as informações, os relatos e os textos etnográficos sobre os grupos dessa região, apontavam, ainda, para um período em que a prática do cultivo parecia muito recente, o que me levou, inexoravelmente, a um escrutínio sobre as noções de agricultura e coleta, fugindo da Grande Narrativa, que nos embala até os dias de hoje, de um percurso progressivo das populações nômades, baseadas numa economia caçadora-coletora rumo às complexas sociedades agrícolas. Dessa maneira, sob inevitáveis e necessários deslocamentos teórico-metodológicos, este empreendimento tem me provocado instigantes aproximações com a arqueologia amazônica e os estudos de ecologia histórica, desvelando uma série de novos temas (ou velhos temas, mas sob novos olhares) sobre a relação Natureza/Cultura, que tenho me dedicado ultimamente.

\section{Como está se configurando a presença dos estudantes indígenas no PPGAS? Quais são os planos de longo prazo para aprofundar e manter viva essa presença?}

Num gesto pioneiro na antropologia brasileira, o PPGAS/UFAM instituiu sua política de ação afirmativa no ano de 2010. No caloroso debate que sustentou esta decisão, eu defendia o argumento de que, a abertura do Programa para a entrada de estudantes indígenas deveria ser motivada por um interesse político-intelectual mais significativo e contundente que a simples benevolência da "justiça social", bastante propalada à época. Tenho quase certeza de que este não foi o argumento vencedor, mas é ele que continua a me embalar na crença de que temos muito a ganhar com epistemologias outras que venham oxigenar a disciplina, sobretudo no contexto (pan)amazônico. Nessa época, eu, juntamente com meu colega Carlos Machado, estávamos bastante animados com a possibilidade de colocar em ação uma proposta que trouxesse algo novo, isto é, em que os indígenas - não necessariamente os estudantes - pudessem ter mais espaço na discussão e produção antropológicas que estávamos inaugurando na UFAM, a partir da criação do PPGAS. Falávamos de uma "antropologia cruzada", em que os "intelectuais indígenas", assim como fazemos nós antropólogos, pudessem ser estimulados a lançar mão de suas balizas epistemológicas para expressar suas concepções sobre os fenômenos sociais observados por eles. Neste contexto, chegamos a elaborar um projeto ambicioso, de reunir conhecedores indígenas de diferentes procedências culturais e geográficas para conversar entre si, motivados por certos interesses antropológicos; publicamos, em co-autoria, um artigo ("Ciência da floresta: por uma antropologia plural, simétrica e cruzada") explicitando todas estas idéias, desejos e motivações. Neste momento, vale dizer ainda, acabava de ser publicado em língua portuguesa, o livro "A Invenção da Cultura", de Roy Wagner (que no ano seguinte esteve entre nós em Manaus numa série de atividades), chamando a atenção para o deslocamento necessário da disciplina em direção a uma antropologia simétrica, o que em muito ressoava com o que estávamos vislumbrando, ainda que de forma intelectualmente mais modesta, porém, experimental e factível. Com a entrada dos estudantes no programa de pós-graduação, esses interesses voltaram-se para o interior da antropologia acadêmica. Em 2010, também, ingressaram no Mestrado os primeiros alunos indígenas, e a partir daí - com exceção do ano de 2014, por uma decisão desastrosa da então direção da Pró-Reitoria de Pesquisa e Pós-Graduação da UFAM -, todos os anos o Programa passou a receber, em média, três estudantes indígenas, ingressos pelo processo de vagas reservadas para atender sua política afirmativa. Hoje, o PPGAS conta com mais de trinta alunos indígenas, de diferentes origens étnicas e territoriais. 
Cerca de um terço desse número participa diretamente do Núcleo de Estudos da Amazônia Indígena (NEAI), do qual faço parte como coordenador e onde tentamos levar adiante aqueles princípios ("argumentos"), já mencionados, que nos fazem crer numa real contribuição para a disciplina, isto é, onde os indígenas não sejam apenas aprendizes e orientandos, mas também, e acima de tudo, interlocutores e protagonistas do saber. Mas é importante deixar claro aqui que este papel, ou este "exercício", a que estes estudantes são submetidos, não é uma tarefa fácil. Evidenciar um conhecimento outro, que possa, de certa forma, impactar a disciplina, exige um deslocamento significativo no fluxo de apreensão e sucesso da carreira acadêmica que estes alunos conquistaram ao longo dos anos no processo educacional formal. Essa discussão é longa e merece extensão, mas me atenho aqui a dizer que uma epistemologia indígena, expressa por novos conceitos e categorias, só pode germinar sobre as ruínas do palácio científico, dos escombros ou dos deslocamentos de nossas ferramentas de construção da alvenaria do edifício do conhecimento antropológico. Mas sei que nem todos os professores, e alunos indígenas do Programa, tem essa visão e este interesse em fazer esse "tipo de antropologia" - o que pode ser salutar para a diversidade e a riqueza da disciplina e para o curso em particular. Entre os anos de 2013 a 2016, o NEAI foi responsável pela condução do projeto Rios e Redes na Amazônia Indígena, que contou com uma frente sobre produção de conhecimentos indígenas em seus próprios termos. Seu resultado foi a publicação de cinco livros, lançados em 2019, e que granjeou a atenção de muitos estudiosos da Antropologia, mas também de um público menos especialista, mas interessado no tema. Você me pergunta "quais são os planos de longo prazo para aprofundar e manter viva essa presença”. Eu diria que cabe, tanto a nós professores quanto aos estudantes do PPGAS, que não são poucos, tal resposta. Pessoalmente, diria que a chama da minha esperança continua acesa, embora confesso que, muitas vezes, dado o esforço quase exaustivo, que tenho que repetir a cada vez que um novo aluno indígena me aparece para orientar, me faz pensar se tenho forças para continuar nessa tarefa de desconstrução dos edifícios das verdades científicas para fazer erigir novas categorias e conceitos indígenas. Às vezes, nos momentos mais cruentos desse esforço, me sinto numa tarefa sisifista. Até o ano passado (2019), os quatro alunos indígenas do doutorado do PPGAS estavam sob minha orientação. Sinto-me honrado e privilegiado com isso, claro, e sei o quanto aprendo com eles, mas sei também o quanto tenho que me dedicar para fazer com que algo novo possa aparecer desses trabalhos, perceber onde pode ser encontrada a força e a criatividade de expressão do conhecimento de cada um.

Quais serão os desafios futuros dessa convivência de diferentes cosmologias dentro de um único programa de pós-graduação?

Um programa de pós-graduação em Antropologia, por si só, é (ou deveria ser) um espaço heterogêneo, de diversidade de corpos, idéias, abordagens e experiências. Portanto, o desafio é intrínseco e impossível não ser vivido e enfrentado dessa maneira. Embora eu não consiga enxergar uma paisagem diferente desta (e talvez ela exista na cabeça e no desejo de alguns, alunos e professores, dentro ou fora da Antropologia), o cultivo da monocultura epistemológica (ou cosmológica, como sugere a pergunta) levaria um programa ao raquitismo e à inocuidade. Pensar algo assim no âmbito da pós-graduação em Antropologia da UFAM seria situá-lo completamente fora do seu próprio chão, a Amazônia, úmida de grupos, comunidades e povos indígenas e tradicionais. Pelo contrário, vejo o PPGAS como um programa cada vez mais rico em sua diversidade sócio-epistemológica, e o desafio da "convivência de diferentes cosmologias" deve ser experimentado por todos nós, alunos e professores, tendo como farol o que há de mais nobre na disciplina em que fomos forjados. Mas, o fato de existir sujeitos de distintas tradições não garante, per se, a superação dos desafios da "boa convivência". Neste caso, a própria natureza e conteúdo 
da disciplina deve ser nosso melhor auxílio, pelo menos intelectual, e a riqueza da presença de distintas vertentes epistemológicas - e aqui me refiro aos alunos, principalmente - pode nos fazer enxergar o desafio da convivência em outros patamares que não apenas aqueles perpetrados pelo Estado de direito, ou pelos direitos forjados nos limites do Estado. Outro nível da diferença, presente na Antropologia, é dado pela sua heterogeneidade das abordagens teóricas, o que é deveras salutar para a força de um programa. Agora, existe outro rol de diferenças, que atravessa as pessoas, constituído pelo ciúme, a inveja, a disputa e a vaidade acadêmicas. A estas, a antropologia pouco ajuda, e devem ser deixadas de lado se queremos avançar numa verdadeira política, intelectual e acadêmica, para enfrentar com sabedoria as diferenças cosmológicas cada vez mais crescentes no PPGAS.

Recebido em 09/05/2020

Aceito em 01/06/2020 